\title{
The biomechanical aspects of pedestrian protection
}

\section{Krishnakanth Aekbote, Peter J. Schuster, Sunny V. Kankanala, Srinivasan Sundararajan and Stephen W. Rouhana}

\author{
Vehicle Safety Research \& Development Department, \\ Ford Rescarch Labs, Ford Motor Company, Dearborn, \\ MI 48124, USA. \\ E-mail: kackboteda ford.com
}

\begin{abstract}
In this paper a biomechanical basis for pedestrian protection is presented based on reviews of epidemiological and biomechanical studies conducted over the last three decades. Epidemiological studies reveal the nature and cause of pedestrian crashes and injuries sustained in the lield. The various factors that influence pedestrian crashes and fatalities such as pedestrian demogaphies, time and location of crash. type of veluicles involved and their design characteristics, impact specds, and nature and severity of injuries sustained are covered in the epidemiology section. The biomechanical studies identify the injury mechanisms and the biomechanical toleranees. Several biomechanical studies that attempt to identify the injury mechanisms and guantify the tolerances are critically reviewed in this paper. and the existing gaps in literature are identified. Further, the three primaty injury mechanisms for pedestrian lower extremity injuries are highlighted. and an injury mechanism for depressed tibial fracture is hypothesized. The effect of exterior velicle parameters such as bumper height, bumper stiffness, hood length, hood stiffiness, bumper lead angle on the nature and severity of injuries sustained are also discussed. The biomechanical injury criteria and tolerance values in a proposed draft ECle pedestrian regulation are also presented. Finally conclusions are drawn based on the epidemiological and biomechanical studies, which lead to a proposal for future work.
\end{abstract}

Keywords: Biomechanies: casls; epidemiology; head; injury; knee; lateral impact; lower leg: pedestrian; safety.

Reference to this patper should be made als folkows: Ackbote. K., Schuster. P.J., Kankanalal, S.V., Sundararajan, S. and Rouhana, S.W. (2003) The biomechanical aspects of pedestrian protection', Imt. J. Velhicle Iesigh. Vol. 32. Nos. 1/2, pp. 28.52.

Biographical notes: Krish Aekbote has a BSS and MS in Meclannical Engineering and is currently pursuing a PhD in Biomedical Enginecring in the area of brain injury. Ife has 10 years of experience in automotive salety and biomechanics. He has worked in the areas of human ankle injury, oceupant protection for side impact and from impact, advanced restraints, elderly biomechanics, post-crash signaling system, pedestrian protection and development of math models. He currently holds the position of Lead Crash Development Engineer at ford Molor Company.

Peter Schuster has a $B \Lambda$ in physics, and an MS and PhI) in Mechanical Engineering. His doctoral rescarch consisted of developing and validating of a linite element model of a human lower extremity in order to investigate 
pedestrian-vehicle injury mechanisms. He has extensive experience in varrous structural aspects of pedestrian protection including bumper, fender. and hood design, in addition to biomechanics and pedestrian kinematies. He chairs the pedestrian working group at Ford Motor Company and is currently a Technical Specialist in Pedestrian Protection.

Sunny Kankanala hats a BS in Mathematics and Mechanical Engineering. MS in Applied Mechanics and is currently a doctoral candidate in Aerospace langineering. He hats extensive experience in design and development of occupant restraint systems and pedestrian protection technology. mathematical modeling and mechanies of adaptive materials and their application in advanced safely systems.

Srini Sundaramajan has a BS in Acrospace Engineering and MS in Engineering Mechanics and Biomechanies. Ite is currently a doctoral candidate in Biomedical Enginecring. He hats 15 years of atulomotive salfety experience in the areas of oecupant protection for front, side and reall impact modes, advanced restraints development, atutomatic collision notification and elderly biomechanics. He is the recipient of 1995 Henry ford Technology Award given for outstanding technical achievement. He is currently at Technical Specialist at the Scientilic Research Labs, lord Motor Company.

Stephen W. Rouhana is a Staff Technical Specialist in the Salfety Research and Development Department of the Ford Scientific Research Laboratories. He currently leads the Adranced Oecupant Protection Group in the Salfety Research and Development Department. Ile received MS and PhI degress in physics from Renssclace Polytechnic Institute. Dr. Roulama is a member of the Joln Paul Stapp Association and is on the Stapp Calr Crash Conference Advisory Committee. He is currently engaged in atutomotive salety research, and his particular areas of interest are impact biomechanles. the development of injury assessment strategies and development of advaneed salfety concepts. Ile has published his research findings in more than 35 technical papers in a number of technical journals, has written al chatpter titled 'Biomechanies of Abdominal Tratumi' which was published in 1993 and 2001 in the book Accidental Inimary: Biomechamics and Pren'muion.

\section{Introduction}

The issue of pedestrian protection has led to a variety of epidemiologicall and biomechanical studies conducted over the last three decades. Significant progress hats been made in understanding the nature of pedestrian crashes, injuries sustained, and the underlying injury mechanisms. The nature and cause of pedestrian crashes and injuries sustanined in field are revealed by epictemiological studies. By conducting biomechanical investigations, the mechanisms of the injuries sustained and the biomechanical injury tolerances are identified. Biomechanical studies attempt to simulate the real world injuries in a controlled enviromment, and relate the mechanical imput parameters (fores, moments, acecterations, etc.) to the resulting injury severity in terms of $A$ bbreviated lnjury Scale (AIS). The $A$ IS mumerical rating system ranges from zero (no injury) to six (maximum) and is a measure of the 
mortality or threat to life (higher AIS level means increased threat to life). This paper covers both the epidemiological and biomechanical aspects of pedestrian protection.

\section{Epidemiology}

\subsection{Crash statistics}

In 1996, approximately 41,800 people were killed in the US due to traffic aceidents. Pedestrian fatalities as a percentage of overall fatalities accounted for $11.3 \%$, and passenger car and light truck occupants accounted for approx. 76.3\%. Although the ratio of pedestrian accidents $(85,000)$ to overall traffic accidents was only $1.2 \%$, they accounted for $13.6 \%$ of fatal crashes $(5090)$, and $3.3 \%$ of injurious crashes $(75.000)$ [1]. Given the involvement rate of 1.2\%, the number of fatalities is disproportionale. This implies an increased risk of fatality in a pedestrian crash relative to other crashes. One cause of this disproportionate risk is clearly the mass and stiffness difference between a vehicle and a person. Table I provides a summary of accident and fatality rates for the US. This increased severity may also be related to a number of factors - Blood Alcohol Level $(B \Lambda C)$, weather, time of day, location of crash. speed of impacting vehicle, age of pedestrian, and the driver age among the major fictors.

As noted in Table 1, almost half of the pedestrian fatalities are related to high blood alcohol levels, which may lead to a decrement in cognitive and sensory function, resulting in an increase in perception/reaction times. Additionally, research has shown that risk of injury is higher with alcohol in the blood than without.

Table 2 summarizes the pedestrian accident statistics in other countries. The datal indicates that in the United Kingdom and Japan, pedestrian fatalities accounted for $26 \%$ and $28 \%$ of all traflic fatalities, respectively. In the Republic of Korcal. pedestrians accounted for $37 \%$ of traffic deaths. Consequently, pedestrians in other countries seem to face a higher risk of fatality and injury from traflic accidents compared to those in US.

Table 1 US accident statistics [1]

\begin{tabular}{|c|c|c|c|}
\hline Type & Podestrian & Toral & "is of lotal \\
\hline latal crashes & 5,090 & 37.351 & 1.3 .6 \\
\hline lujurious crashes & 75.000 & $2,256.000$ & 3.3 \\
\hline All crashes (fatal + injurious + prop. damage) & 85,000 & $6,394,000$ & 1.2 \\
\hline Persons killed & 4,739 & 41.821 & 11.3 \\
\hline liatiality rate (per 100,000 population) & 2.04 & 1.5 .2 & \\
\hline Persons injured & 78,000 & $3.189,000$ & 2.4 \\
\hline Alcolsol related deaths $(B \wedge C>0.1 \mathrm{~g} / \mathrm{dl})$ & 2.227 & 16.653 & 1.3 .4 \\
\hline Percent & $47 \%$ & $40 \%$ & \\
\hline
\end{tabular}


Table 2 Accident statistics in other countries [2]

\begin{tabular}{|c|c|c|c|c|}
\hline \multirow[b]{2}{*}{ conmtry' } & \multicolumn{4}{|c|}{ Fatalitics } \\
\hline & Tolal tralfic & Podestrian & $\begin{array}{c}\text { Perkestrian as a } \\
\text { "yof ototal }\end{array}$ & $\begin{array}{c}\text { Pedestrian per } \\
\text { to0,000 population }\end{array}$ \\
\hline France & 8,918 & 1,044 & 11.7 & 1.27 \\
\hline Germany & 7.792 & 1.084 & 13.9 & 1.32 \\
\hline Italy & 6,326 & 846 & 13.4 & 1.47 \\
\hline Japan & 10.805 & 3,057 & 28.3 & 2.42 \\
\hline Korea (Rep. of) & 10,416 & 3,874 & 37.2 & 8.42 \\
\hline Netherlands & 1.060 & 110 & 10.3 & 0.70 \\
\hline Spain & 5.957 & 995 & 16.7 & 2.53 \\
\hline Sweden & 531 & 69 & 13.0 & 0.78 \\
\hline UK & 3.581 & 946 & 26.4 & 1.60 \\
\hline
\end{tabular}

\subsection{Where and when pedestrian crashes occur?}

The circumstances leading to pedestrian crashes have been hypothesized based on accident reconstruction, and driver/pedestrian/witness reports. The NASS database categorizes pedestrian crashes into two types: Intersection and Non-intersection crashes [1]. Table 3 shows the location of the crashes for the year 1996.

The NASS database also reports the factors related to pedestrian faltalities $30.5 \%$ of them were due to walking, playing, working, clc, in roadway, while $30.5 \%$ were due to improper crossing of roadway or intersection, and $28 \%$ were due to darting/running into road or failure to yield right of way. The PCDS reported that $86 \%$ of the pedestrians were attempting to cross the roadwaly prior to crash. suggesting that they were impacted on the side by the oncoming vehicle. Also, the pre-crash attention of the driver was noted as a factor. $60 \%$ of the drivers indicated that the vehicle was moving straight. During a turning maneuver, a pedestrian was more likely to be struck in a left turn. This was apparently due to the driver's attention focused on oncoming traftic while wating for the traffic to clear, and failing to notice the pedestrian. In $68 \%$ of the cases, the driver"s critical crash event was the pedestrian on the roadwaty, and the driver intended to continue straight through the intersection. This imples that the pedestrian did not have the right of way. About $43 \%$ of the drivers engaged in an avoidance maneuver. usually braking. and some stecring $[3,4]$. Table 4 shows the occurrence of fatal/injurious crashes by

Table 3 Perentage of pedestrians killed/injured 1996

\begin{tabular}{lcc}
\hline Location of crash & Killed & Injured \\
\hline Intersection & $23 \%$ & $36.4 \%$ \\
Non-intersection & $77 \%$ & $60.7 \%$ \\
\hline
\end{tabular}




\begin{tabular}{llc}
\hline Time of de! & Killed & Ininired \\
\hline $6 \mathrm{Am} 6 \mathrm{PM}$ & $34.8 \%$ & $63.7 \%$ \\
$6 \mathrm{pm}$ midnight & $47.6 \%$ & $30 \%$ \\
\hline
\end{tabular}

time of daly. Almost half of the fatalities occur from 6 pM-midnight, while $64 \%$ of the injurious crashes happen during the day especially, during peak hours' INHTSA. 1996].

Most pedestrian crashes occur in city or residential streets where the population density is high $[1,3-6]$. This is evident from the higher accident rates in Japan. the UK, and other European countries that have high level of urbanization.

\subsection{Vehiches involved and characteristics}

In the US during 1996, passenger cars were involved in $54 \%$ of fatal pedestrian crashes and $72 \%$ of injurious crashes, whereas light trucks were involved in $32 \%$ of fatal crashes and $25 \%$ of injurious crashes. The pedestrian was impacted by the front of the velice in $90 \%$ of the fatal crashes and $70 \%$ of the injury crashes [NHTSA. 1996]. The Pedestrian Crash Data Study (PCDS) analysis reported passenger car involvement at $71 \%$ and light trucks at $29 \%$. This composition was proportional 10 the registration of cars and trucks in the US [3-6]. Out of a total of 2180 injuries for 292 pedestrians, 66\% were from passenger car impacts, 15\% from pick-up trucks. and $8 \%$ from SUV's. Further, $60 \%$ of the serious injuries ( $\triangle \mathrm{IS} 3-\Lambda \mathrm{IS} 5$ ) resulted from passenger cars, while pick-up's and SUV's contributed 22\% and 6\% respectively.

Based on the analysis of real world accident data reported by many researchers. pedestrian contact with different vehicle regions produced injuries to different body regions of varying severity (AIS 1-5). Children and adults sustained different injuries, though the velicle contact regions were similar. Children sustained more injuries to the head, femur, and pelvis due to contact with the hood and hood-edge. while adults sustained lower leg and femur/pelvis injuries. Table 5 shows the distribution of vehicle contact areals and $\triangle I S$, as reported in the PCDS. Almost 24\% of the 2180 injuries reported were caused by contact with ground, and $6 \%$ due 10 unknown source [4]. From Table 5, it is evident that contact with the front bumper of the vehicle is associated with $20 \%$ of the injuries sustained by pedestrians. Of these. $76 \%$ are minor injuries ( $\mathrm{ISS} 1-2$ ), and 24\% are serious injuries ( $\mathrm{IS}$ 3-5). Also, front bumper accounts for $20 \%$ of all minor injuries and $21 \%$ of all serious injuries sustained by pedestrians. Windshield is associated with a similar number of injuries. Other studies have reported similar findings [7-10]. In general, the front bumper is associated with lower leg/knee injuries in adults, and femur injuries in children. The hood surface is associated with head, femur, and chest injuries in adults, and head injuries in children. The likely head impact locations for children fall on the twothirds of the hood surface closest to the hood edge, while for adults the location is closer to the windshicld [8]. The hood edge is associated with femur/pelvis injuries in adults, and femur/pelvis/chest/abdominal injuries in children [7-9]. 


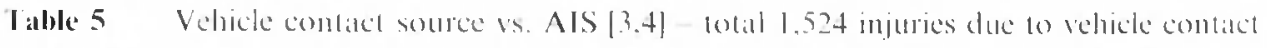

\begin{tabular}{|c|c|c|c|}
\hline \multirow[b]{2}{*}{ Vohick combact } & \multirow{2}{*}{ 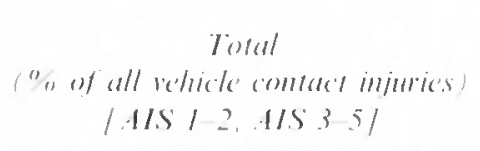 } & \multicolumn{2}{|c|}{ "of all whiche combert imjurices } \\
\hline & & $\begin{array}{l}\text { Minor } \\
\text { HSS / 2) }\end{array}$ & $\begin{array}{l}\text { Mujor } \\
\text { lls } 35\end{array}$ \\
\hline froml bumper & $20 \% / 176 \%, 24 \% / 1$ & $20 \%$ & $21 \%$ \\
\hline Hond edge & $11 \% 171 \% .29 \% 1$ & $10 \%$ & $1.3 \%$ \\
\hline Hood surlitec & $14 \% \mid 82.5 \%, 17.5 \% 1$ & $15 \%$ & $10 \%$ \\
\hline Reinforeed hood & $4.5 \% 0[66 \%, 34 \% " n]$ & $4 \%$ & $7 \%$ \\
\hline Windshick & $21 \% 174 \%, 26 \% 11$ & $20 \%$ & $24 \%$ \\
\hline A-pillal & $5 \% 10157 \%, 43 \%$ & $4 \%$ & $10 \%$ \\
\hline Front lender & $4 \%,[94 \%, 60 \%]$ & $5 \%$ & $1 \%$ \\
\hline Cowl arcal & $2010,72 \%, 28 \%$ & $1 \%$ & $5 \% " 1$ \\
\hline
\end{tabular}

The primary parameters reported in the literature that influence the veltickpedestrian kinemalties and injury outcome are: bumper height from ground, hood edge heiglu from ground. angle of hood, angle of wind shield. length of hood, bumper kead lengll or bumper lead angle |4.11]. These are shown in Figure 1.

\subsection{Impret ipereds}

Impact speed is one of the most dilfiedt parancters to determine in a pedestrian accident investigation. The impace speed is one of the primary determinants of injury outcome of a crastr. Several in-depth studies of accident investigations have tried to correlate impact speeds 10 injury in pedestrian alecidents alt speeds lower than $58 \mathrm{~km}$ 1). They also noted that 50\% of all pedestrian fatalities occur alt speeds less than $50 \mathrm{~km} / \mathrm{h}$. and there were no latalities below $25 \mathrm{~km} / \mathrm{h}$. Figure 2 shows the reditionship between impact speed and AIS ats determined in the PCIOS [4].

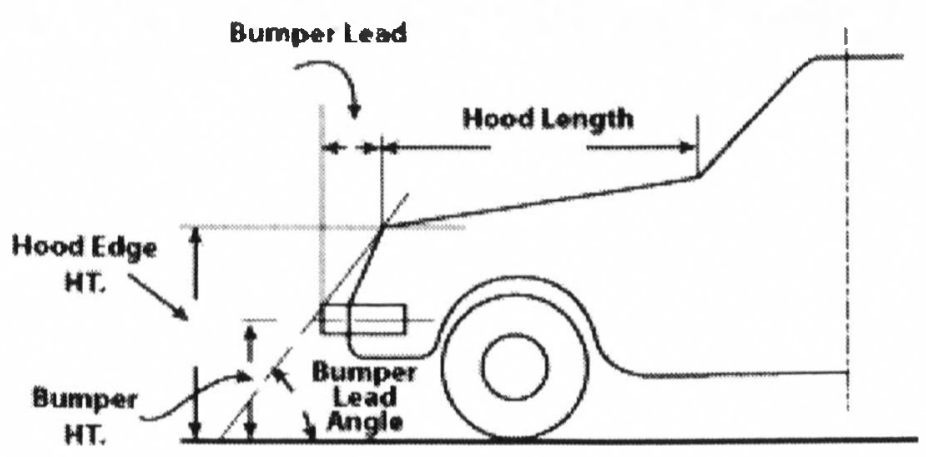

Figure I Vebicke patrameters influencing pedestrian kinematics 


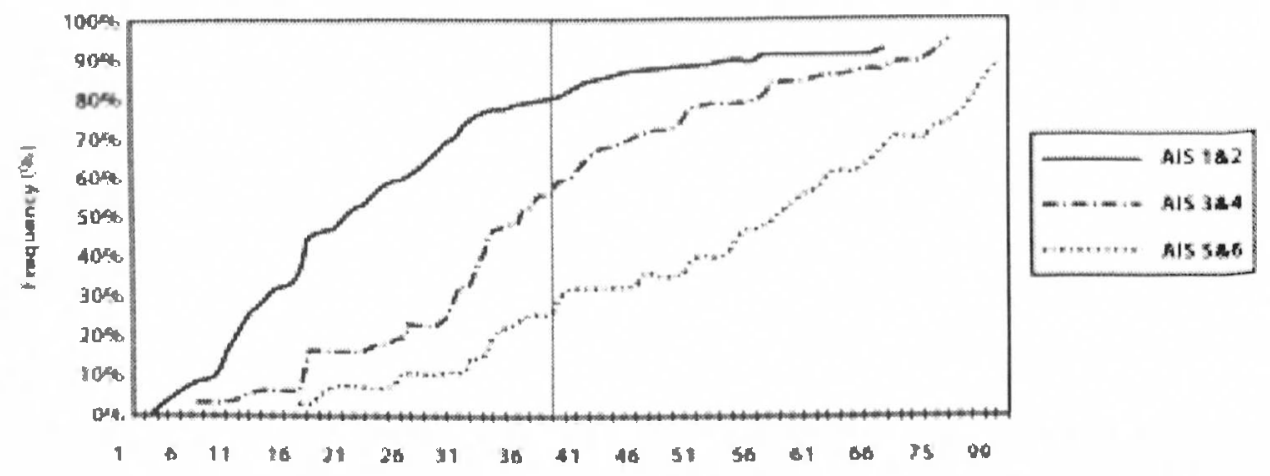

Impor Ipared Itmin

Figure 2 Impace speed ws. AIS [4]

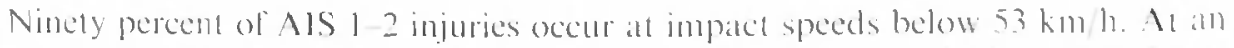
impact speed of $40 \mathrm{~km}$ h and below, $80 \%$ of all AIS $1-2$ injuries. $60 \%$ of all AIS $3+$ injuries, and $30^{\circ} \%$ of all AIS 5 o injuries occur. Figure 2 shows that the AIS 1 2 curve rises shatply with speed initially and then lantens out, demonstrating the high incidence of AIS 1 - 2 injuries at lower speeds. Given an impatet speed. the vartaltion in the AIS levels suggest that parameters other than impated speed also contribute to the injury severity.

\subsection{Pedestrian demographics}

Age is one of the most important latelors in determining the severity outcome of at crish. It has been shown in the literature that children (0) 1.5 years) and the eleterly $(>0,5$ years) are disproportionately involved in latal and serious injury crashes compared to the rest of the population |1]. In an older study, EEV reported the latalities of pedestrians over ot years old, ats a pereentage of all pedestrian fatalities $35.4 \%$ France: 47\% - Cemany: 40.4\% - UK: and 48.6\% - laily [7]. An indicaltion of the risk fiaced by pedestlians in at certain age group can be oblained by normatizing the fatalities in that age group to the population at risk (fatiality rate per $100(0)$ (o) persons). The pedestrian latlality late was 1.2 for children. 2 .0 for adults, and 3.5 for elderly in the US [NHTSA. 1996]. Compared to the rates for the adults in tis. whe rates are much higher in European countries during the 1970s: for the elderly 15.6

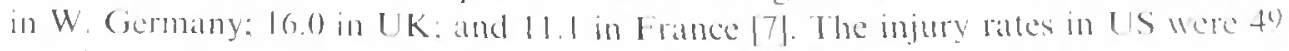
for childeren. and 18 for the elderly [NHTSA, 1996]. Batsed on the accideme statistics for Europe. the edderly are exposed to the highest risk followed by the children.

Several in-depth lïeld investigations of pedestrian alecidents in US and dapaln hance

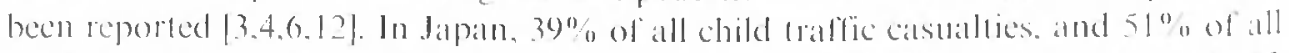
child trallic batalities are due to pedestrian accidents |121. From an analysis of 29) pedestrian crashes in the US, the involvement of children and elderly were 20" o and 9\% respectively 13.41. Another study investigating 217 pedestrian latalities in the IS

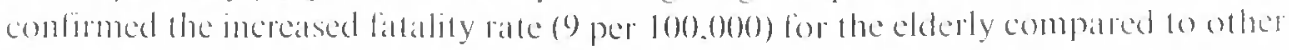
age groups (2 per $100,0(0) 0)|0|$. 
Pedestrian height is another important physical attribute in governing the dynamies of a crash. The severity of crash and type of injuries sustained depends on the relative height of the vehicle (bumper and hood edge) and the pedestrian (knee and hip height). A taller pedestrian mat be more prone to head injuries due to contact with the windshield surround, while al shorter pedestrian may be at a higher risk for femur/pelvis injuries due to hood leading edge contact. Very few studies have reported the overall height of pedestrians. One such study is the Pedestrian Crash Data Study (PCDS) initiated by NHTSA in 1994. Of the 292 crashes reported. 19\% of the pedestrians were $5 \mathrm{ft}(60 \mathrm{in}$ or $152 \mathrm{~cm})$ or under, $36 \%$ were between $5 \mathrm{ft}-5 \mathrm{ft} 6 \mathrm{in}$ $(61-66 \mathrm{in}$ or $155-168 \mathrm{~cm}), 28 \%$ were between $5 \mathrm{ft} 7 \mathrm{in}-6 \mathrm{ft}(67-72 \mathrm{in}$ or $170-183 \mathrm{~cm})$, and $5 \%$ were taller than 6 fi $(72$ in $[3,4]$. Pedestrians between $5 \mathrm{ft}-5 \mathrm{ft} 6$ in sustained mostly minor injuries (MAIS1-MAIS2), while those between $5 \mathrm{ft} 7 \mathrm{in}-6 \mathrm{ft}$ sustimed serious injuries (MAIS3-MAIS5).

\subsection{Bod!y regions and severity of pedestrian injuries}

One of the problems encountered in the literature was inconsistency of injury sealing. some studies classified the injury as minor and non-minor, while others classified based on AIS-85 scale. Additionally, the definition of minor and non-minor injuries varied between studies, and the definition of body regions was also inconsistent.

Isenberg e $a l$. indicated that $68 \%$ of all pedestrian crashes resulted in MAIS 1-2 level injuries, and 30\% resulted in MAIS 3-6 level injuries. Considering injuries AIS 2 and above, the body regions most injured were head $(32 \%)$, lower extrenity $(31 \%)$, upper extremity $(9 \%)$, followed by abdomen, chest, and face $(7 \%$ each $)[3,4]$. Another study reported that in fatal pedestrian accidents the most severely injured body regions were the head/neck/face $(64 \%)$, the chest $(12 \%)$, and the abdomen $(8 \%)$. Among the non-fatal crashes, the body regions injured were the lower extremities $(40 \%)$, the head $(32 \%)$, the arm $(12 \%)$, and the hip $(10 \%)$. The same study found that the lower extremities $(36 \%)$, the head $(24 \%)$, and the chest $(11 \%)$ were the most injured when considering AIS $2+$ injuries [10].

\section{Biomechanical aspects}

\subsection{Orervien of rehicke-pedestrian kinematics}

When a pedestrian is struck by the front of a car or a light truck/mini-van, the first contacts are ustually with the bumper and/or the front edge of the hood depending on the shape of the vehicle front end. The region of contact on the pedestrian depends on the relative height of the pedestrian and vehicle front. For example, with small children the bumper may contact the upper leg and the leading edge of the hood may contact the chest. For addults the bumper may contact the lower leg/knee and the edge of the hood contact the femur/pelvis. The pedestrian may 'wrap-alround' and slide over the front edge of the hood. This may allow the head and chest to contact the surface of hood/windshield. The location of this contact depends again on the relative height of the pedestrian and the geometry of the velicle front end (length of hood, height of hood edge). At lower speeds $(<20 \mathrm{~km} / \mathrm{h})$, the second plase of impact - the 
"wrap-around' or lateral bending of the pedestrian around the edge of hood, may nol occur.

If the impact speeds are very high $(>60 \mathrm{~km} / \mathrm{h})$, the pedestrian may rotate aboll the second contact point (e.g. the head) and the whole body may contact the leading edge of the roof.

The forces resulting from contact with the vehicle front end accelerates the pedestrian up to the speed of the impacting vehicle. If there is braking of the vehicle, as the vehicle begins to decelerate, the pedestrian may move ahead of the vehicle and strike the ground [13]. This distance from the initial contact on the vehicle to the fina] impact point on the ground is commonly known as 'throw distance'. For example, al an impact speed of $40 \mathrm{~km} / \mathrm{h}$, the throw distance may be approximately $15 \mathrm{~m}$.

The contact with the pedestrian may result in 'translation' and 'rotation' aboul anterior-posterior axis. The relative amount of each determines the pedestrial) kinematics, which depend on the relative location of resultant contact foree and $\mathrm{C}_{\mathbf{i}}$ of the body. If the impact is below the knee, the pedestrian mat experience more rotation than transtation. Also, as the speed increases, the likelihood of the head contact with the windshield also increases. Pedestrian kinematics is quite complex and depends on many factors such as impact speed, relative height of pedestrian and vehicle front-end geometry among others.

\subsection{Injury mechanisms}

To redue the likelihood of pedestrian injury, it is helplul to understand the nature of the injuries sustained and the mechanisms of those injuries. Epidemiological studies have indicated the nature and severity of injuries - lower extremities and head are the most frepuently injured body regions. Based on the Gadd Severity Index and the Wayne State Head Injury Tolerance Curve, a biomechanical head injury criterion for contact injuries - "HIC" was established. An injury tolerance value of 1000 (for 361115 duration) was established, and was used for many years in FMVSS 201 and 208 for head impact protection. Therefore, in the following sections, the discussion will be restricted to injury mechanisms of the lower extremity (lower leg, femur and knee), primarily during lateral impact. These injury mechanisms were investigated by the athors of the studies reviewed by conducting cadaver/dummy experiments in the lab, in an attempt to reproduce the injuries seen in lield accidents.

\subsubsection{Experime'ntal studies}

Experimental studies to investigate pedestrian injuries began in early 1960) and became more focused during the 1970s. Several full-scale experimental studies were carried out with whole caldavers and actual velicle front structures. K ramer at al. [14] carried out 209 pendulum tests $(4-8 \mathrm{~m} / \mathrm{s})$ with cadavers to assess the fracture tolerance of tibia. They reported infra-condylar comminuted fractures of the tibia. when the impact was to the proximal tibia. They also noted that there was a high frequency of tibial fractures for older cadavers due to osteoporosis. One of the first full-scale experimental simulations was conducted by Krieger at al. [15] using cadavers and 95th pereentile anthropomorphic dummy at three speeds of 24, 32 and $40 \mathrm{~km} / \mathrm{h}$. The cadavers were impacted in a standing position with $80 \%$ of the body weight on the impacted leg. The linear and angular aceeleration data measured in the 
tests aided in understanding the gross pedestrian kinematies. The influence of velicte front-end geometry and ground friction on pedestrian injuries was first investigated by Pritz et al. [16]. In a series of 15 experiments $(10-30 \mathrm{mph})$, they reported comminuted supracondylar fracures of the femur, comminuted fracture of proximal tibia and separation of tibial intercondylar eminence. They did not report any ligament ruptures. They also observed depression of the lateral tibial plateau, which maly have been indued by the lateral rotation of lower leg and femur about the lateral condyles (of knee) with hip and ankle as valgus pivots. This maty presumably explain the large vertical ground reaction force (twice the body weight) they measured. They suggested that there is a transition in injury severity from 15 mph to 20 mph. Lowering the bumper led to reduction in injury severity to the lower leg, but increased the head impact velocity on the hood.

In another test series, Pritz [17] compared the responses and trajectorics of the modified Part 572 dummies (50th pereentile and 6-year-old child) with eadaver data. He reported that dummy neck and shoulder responses were too stiff compared to the cadaver. Eppinger and Pritz [18] were among the first to report injuries to the anterior $(A C L)$ and posterior cruciate ligaments (PCL), combined with the libial, libular, and condylar fractures of the femur. From full-scale pedestrian tests, based on force-time data, they developed a leg-form impactor having the same effective matss, to simulate the leg interaction with the bumper. Aldman "t al. [19] in a series of component tests using cadaver femurs and lower leg-ankle complexes witl concentrated body mass illustrated the effect of impact location on tibia and corresponding bumper fores. They reported that the bending forec at the knee was lowest when the impact was at the CG of the tibia. They also found that the simulated body matss had a minor influence on the bumper foree and ground friction force except in low speed impacts.

Bunketorp a al. [20] simulated leg injuries from clinical studies in experiments using ampulated femurs and whole legs (hip-femur-lower leg-ankle complex). Malleolar fractures and ligament injuries of the ankle joint were usually associated with bumper contalets at mid-tibia level. They hypothesized that these injuries resulted from shearing force of the distal tibia and the inertia of the accelerating foot. They also observed that at lower velocities, a lower bumper height resulted in undisplaced malleolar fractures of the ankle joint and ligament ruptures, while a higher bumper height resulted in medial collateral ligament (MCL) rupture of the knec joint. At higher velocities, a low bumper height resulted in comminuted fractures of the tibia and/or fibula, while a high bumper height resulted in fractures of the tibial and femoral condyles. It was noted that a llexed knee was more vulnerable to compression lorees than an extended knee. They also suggested a combination of shear foree, bending moment and compression force at the knee joint as an injury mechanism for the knee.

When the lower leg/knee is impacted on the lateral side, it maly bend erealing a compressive forec on the lateral condyle of the tibia and a tensile force on the $\mathrm{MCL}$ and cruciate ligaments. This maly result in compression fractures of the tibial platteatu (also referred to as tibial condyle in literature) and ruptures of the ligaments [21]. $\Lambda$ review of aclult pedestrian injuries and their long-term prognosis was provided by Manoli [22]. He noted that knee injuries could be from valgus bending (due to impact on the lateral side) or varus bending (due to impact on medial side) of the knee. 
Valgus stress maly result in injury to MCL and medial meniscus, and may result in fracture of the lateral tibial plateat. They noted that intra-articular fractures and ligament ruptures of the knee joint could have serious long-term consecuences.

Kallieris et al. [23] in a full-scale simulation with cadavers observed injuries to the spinal column (lumbar and cervical) in addition to wedge fractures of the mid-tibia and oblicue/transverse fractures of the tibial head. He indicated that lumbar spine injuries were associated with 'wrapping' of the pedestrian around the vehicle's frontend, which resulted in bending between thoracic and lumbar vertebrae. The anatomic attachment of the ribs to the thoracie spine makes it less compliant than the lumbar spine. This may result in the maximum bending moment occurring in the lumbar region resulting in injury to the vertebral bodies and discs.

Further investigation to assess the influence of bumper height and impact speed on pedestrian injuries was conducted by Cesari e't al. [24]. In a series of twenty cadaver tests, the bumper forees and knee angles were measured relative to the bumper height. They concluded that bumper force was not a good predictor of injury' risk, since it did not show any correlation to bumper height or the nature of injuries. It can be postulated that the effective mass of the leg may not have changed significantly with impact location (for a given impact speed), so the bumper foree was just proportional to the acceleration of the inertial mass, which did not vary much. They reported no knee joint injuries for bumper heights at, or below, a height corresponding to a level off the floor of $75 \%$ of the lower leg length $(100 \%$ corresponded to knee level). Further, for impacts below knee level, they indicated that knee angle was more dependent on the bumper height than the impact speed. A $65 \%$ bumper height resulted in least amount of valgus rotation. In another series of caldaver experiments, Cesari ef al. [25] reported that a low bumper height reduced the risk of ligament injuries, and higher impace speeds produced bone fractures rather than ligament injuries.

To understand the injury mechanism of the knee joint in pure lateral shear loading, Kajzer et al. [26] conducted low speed $(15-20 \mathrm{~km} / \mathrm{h})$ tests using cadaver lower leg specimens. The test set-up is shown in Figure 3. The load eell near the knee measured the knee reaction force, which was indicative of the shear force through the knee joint. The load cell on the impactor measured the impact force.

Based on obscrvations and analysis of test results, they proposed two injury mechanisms: First they noted that injury was related to the acceleration of the leg and occurred within $5 \mathrm{~ms}$ after impact. These injuries were classified as 'contact' injuries (fracture of the dibial lateral condyle, head of the fibula, and diaphysis fractures of the tibia and fibula). The second observation was related to the force transferred through the knee joint during impact as the thigh was accelerated. This injury occurred about $15-20 \mathrm{~ms}$ after impact, as indicated by the knee reaction force. This mechanism generated intra-articular injuries of the knee such as avulsions rupture of $\mathrm{ACL}, \mathrm{MCL}, \mathrm{LCL}$, fracture of tibial intercondylar eminence and femoral cartilage injury due to the contact between tibial intercondylar eminenee and medial femoral condyle.

Kajzer ef al. [27] extended this approach to determine the injury tolerance of the knee joint when subjected to low speed bending impacts. The legs were impacted at the ankle joint to induce maximum bending moment at the knee joint. As in the previous study, they observed a characteristic double peak for the bending moment 


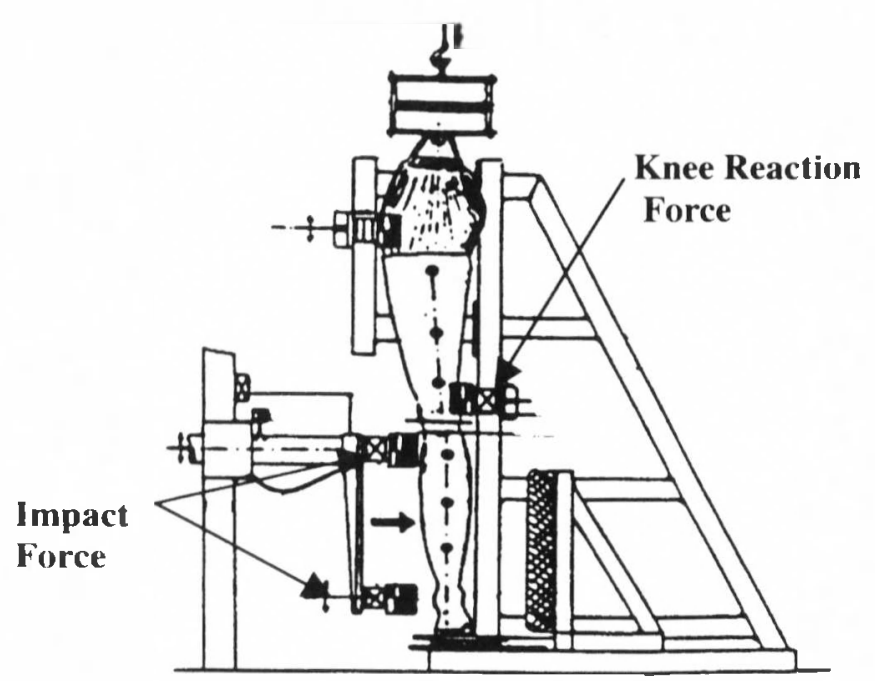

ligure 3 Tesil set-up for pure kateral shear [26]

al the knee joint. The litst peak oceured within 5 ms, and was related to the latilute of MCL. fratelure of medial condyle and or compression fracture of lateral condyle. The second peak occured about $50 \mathrm{~ms}$, and represented the maximat activation of non-damaged knee structures. This may have involved the stretching of ACL and PCL. but did not exceed their folerance limits. Nevertheless. When the knee was subjected to lateral bending. the most frequent injury was partial or total rupture or avulsion of the MCL. In other full-scale tests (pedestran-vehicte impacts) reported in the literature, the knee joint was loaded in bending and sheals. the matgnitude of each depending primatrily on the location of contate with the tibia. In the previous study, the knee joint was in pure shear and therefore may not be representative of the alctual foading condition experienced in crash tests. Also, the mean age of the caldaver specimens lused wals over 75 years of alge.

To address some of the previous concerns, Kajzer a al. [28] conducted another series of high-speed shear lests, and bending lests at $40 \mathrm{~km} / \mathrm{h}$. They modified the lest sel-up for shear to induce a shear foree and bending moment through the knee joint simulancously, and used the sime set-up as betore lor bending lests (Figure 4). The mean age of these cadalver specimens was 51 years.

In this study, the nature of injuries diflered from the previous lests. Typical injuries in shear loading were avulsion of ACL. comminuted supracondylat and comminuted diaphysis liactures of the femur, and ardicular fracture ol the tibial condyle. Figure 5 shows the typical injury patterns observed. The initial injuries observed in bending were avulsion of $\mathrm{MCL} / \mathrm{PCL} / \mathrm{ACL}$, and comminuled suprat-

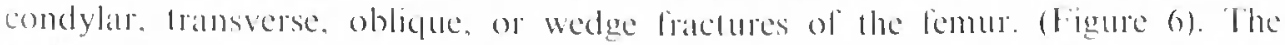
difference in injuries observed between the previous tests and this series was attributed to impart speed. Low velocity impates calused ligament ruptures. While high-speed impacts resulted in liactures and ligament injuries.

In sheale tests, the damage mechamism (of articular latature) was dele fo shearing and small hending deformation of the knee. This led to axial compressive forees 

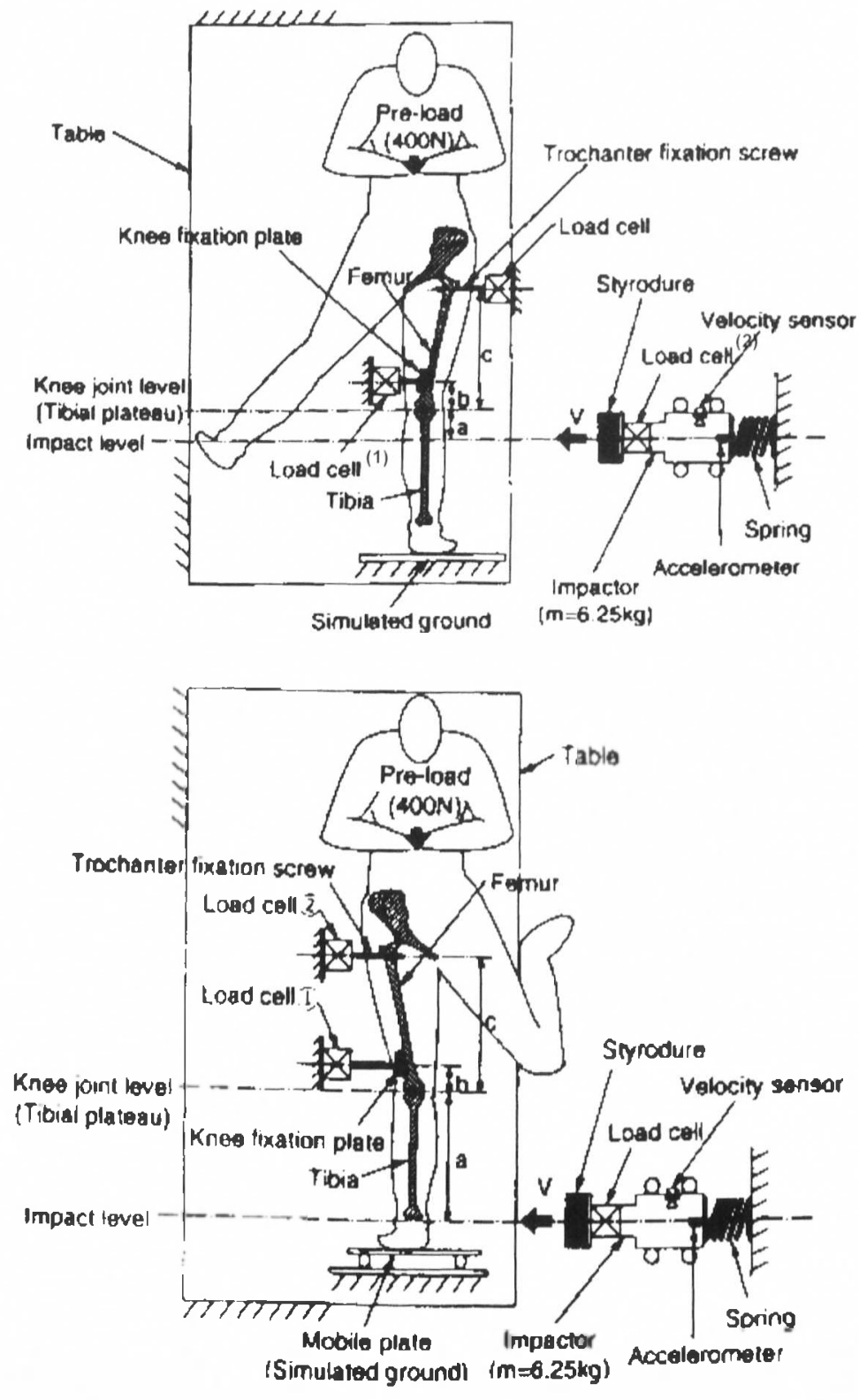

(b)

(Simulated ground $(m=6.25 \mathrm{~kg})$

Figure 4 Test set-up for shear (a), and bending lests (b) |28|

between the femure and hibial eondyles, resulting in articular fractures. The p. , ied mechanism is shown in figure 7. The diaphysis and metaphysis fractures of the femur were attributed to the high stress concentration in the knee from a combination of shear foree and bending moment in both the sheall and bending lests

When these experiments were repeated al lower speeds of $20 \mathrm{~km} / \mathrm{h} / 29 /$. they concluded that boll shear and bending tests caused mathly ligatment injuries (AC 1 in 

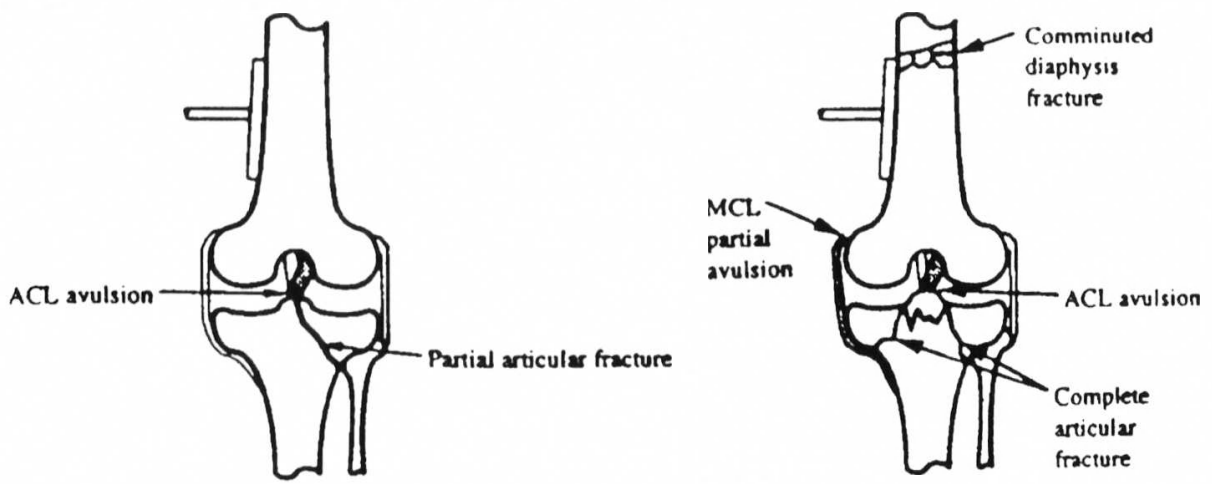

Figure 5 Typical injuries in shear tests [28]
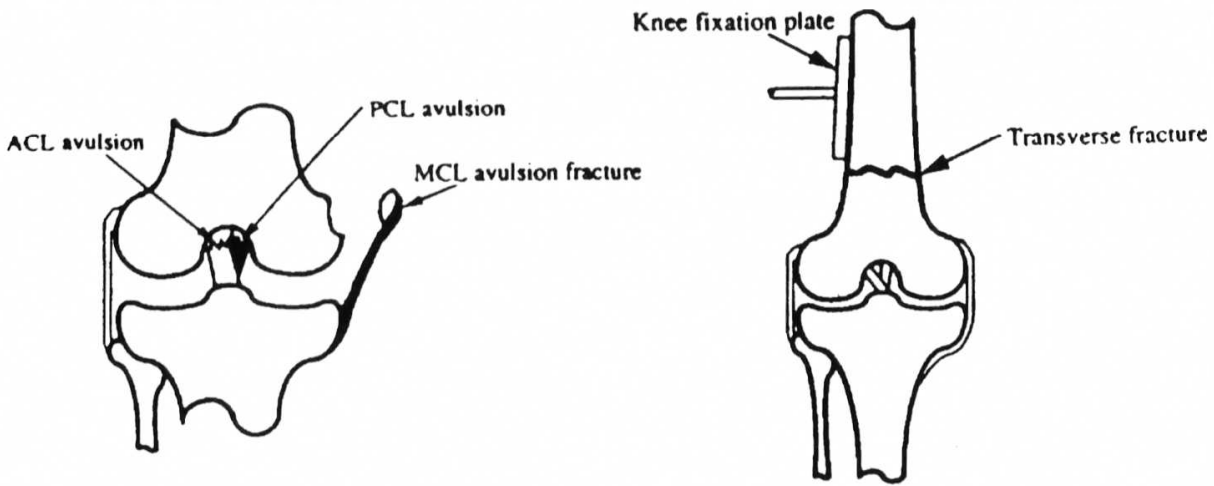

Figure 6 Typical injuries in bending tests [28]

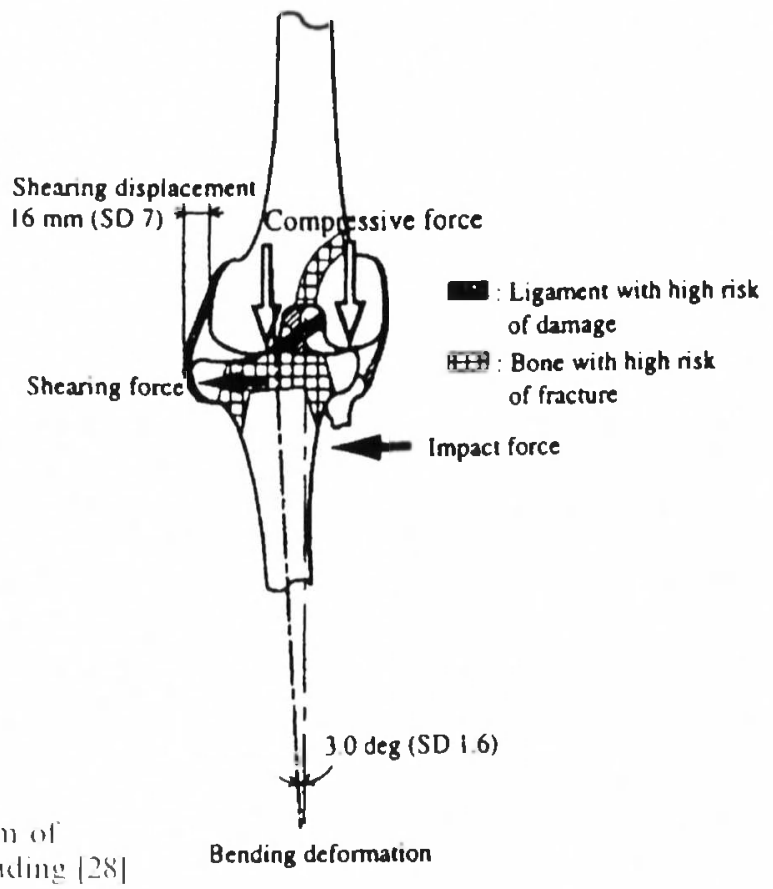


shear loading and MCL in bending) in contrast with bone fractures observed in highspeed tests.

The experimental studies discussed above have investigated and reproduced injuries to the femur, knee, and tibia sustained by pedestrians in real world crashes. In summary, the injuries to the lower extremities have been explained by three proposed primary injury mechanisms:

1 Contact injuries due to acceleration of the leg (fracture of the femur and/or tibial shalft);

2 Injuries due to shear fores through the knee joint ( $\triangle C L$ rupture/avulsion, tibial intercondylar eminence fracture, femoral cartilage injury);

3 Injuries due to bending moment at the knee joint (compression fracture of lateral femur condyle, tibial plateau fractures, and MCL rupture).

\section{2 .2 Mathematical modeling}

Over the past three decades, a variety of mathematical models have been developed. and are still being developed as the knowledge base of different injuries and injury mechanisms is being expanded. This body of knowledge has led to the evolution of more complex models. If valid assumptions are made, and the vital anatomical characteristics and physical properties accounted for, math models have the potential to help uncover the underlying injury mechanisms, under different loading conditions.

Most of the mathematical models of pedestrian impact developed in the 1970s and 1980 s were rigid body based models. They were essentially rigid bodies represented by planes and ellipsoids, and connected by a hinge or spherical joints [30-32]. More mathematically modeled joints (translational, planar, cylindrical and frec) are now available to accurately represent the pedestrian kinematies in 3-D. The complexities of early pedestrian models vary from 3-segment to 15 -segments, in 2-D and 3-D, to represent various body parts and capture the kinemalies. Padgatonkar et al. [30] was among the lirst to develop a 15 segment 3-D model of the pedestrian. to understand the gross motion and fores involved in a pedestrian impact. In the past. model validation was based on trajectories and accelemations of body regions, which were measured in lab tests. Using these criteria it is interesting to note that an increase in complexity of the model from 7-segments to 15 -segments did not lead to a proportional increase in accuracy $[32,33]$.

It is worthwhile to mention that most of the modeling effort in the past has been to understand the effect of vehicle front-end designs on pedestrian kinematics and accelerations. Very little emphasis was placed on understanding the injury mechanisms, until the 1990s. Most recently, Yang and Kajzer [34] developed a 3-D MADYMO rigid-body model of the human knee. The knee joint model included the articular surfaces, ligaments, and capsule, represented by planes, ellipsoids and spring-damper elements. The anatomical coordinates for ligament-bone insertions were captured in the model. It was assumed that ligament stmains of $12 \%$ and $20 \%$ corresponded to partial rupture and complete rupture, respectively. The ligament strains measured in the model correlated well with the experimental observattions. The model was able to predict the lateral condyle contact force, which was higher 
than the impact force. Based on relative elongations, the MCL had the greatest risk of injury, followed by $\Lambda \mathrm{CL}$. Using this model they assessed the influence of upper body mass on the responses and found that, upper body mass influenced every parameter they measured, though the magnitudes were not reported. One of the drawbacks of this model was that the bone factures could not be reproduced. Also, the ligaments, which are highly viscoelastic in reality, were represented by elastic elements. The previous model was improved by adding a fracture joint (at impact location) to simulate contact fractures [35]. The model performance improved, and the condyle contact forces reasonably correlated to condyle fractures observed in tests. Further improvements were made to the model, by incorporating the viscoelastic characteristics of the ligaments and representing the tibial intercondylar eminence in the geometry [36]. Batsed on the results of shear and bending simulations (carried out by Kajzer 't al.), they confirmed some of the mechanisms of knee injury of their previous findings.

It is interesting to note that very few finite element (FE) models of the pedestrian lower limb exist in the literature. The first attempt to develop a full biomechanical model was made by Bermond e't al. in 1994 [37]. This model included the tibia, femur, ACL, LCL, MCL, and PCL, and was designed to simulate pedestrian impacts using PAM-CRASH as the FE solver. The bones were modeled as deformable bodies using linear viscoelastic shell elements: 650 for the femur and 550 for the tibia. Ligaments were modeled as 1-D non-linear linkage elements. Bone geometry was obtained from scanned bone surfaces.

In 1996, Yang 't al. [38] developed a more detailed finite element model of the lower limb including the tibia, femur, $\triangle \mathrm{CL}, \mathrm{LCL}, \mathrm{MCL}, \mathrm{PCL}$, and a simplilied foot for pedestrian impact analysis using DYNA3D as FE solver. The bones were modeled as deformable bodies using linear viscoelastic solid hexalhedron elements: 3072 for the femur and 5364 for the tibia. Collateral ligaments were modeled with a combination of shell and spring elements, while cruciate ligaments were modeled with spring-damper elements. Bone geometry was simplified to reduce the modeling complexity and smooth the contact surfaces.

In 2000, Schuster e' al. [39] and Takahashi at al. [40] independently developed two detailed finite element models of the pedestrian lower limb. Both of these models were based on bone surface data from Viewpoint Datalabs. Each was validated using both individual bone test data and the full lower limb studies conducted by Kajzer et al. These models represent the eurent state of the ant of pedestrian lower limb simulation. No studies related to injury mechanisms have been reported from these FE models yet.

All pedestrian lower limb mathematical models suffer from a lack of biomechanical data. In particular, these models need both static and dynamic non-linear stress-strain curves for cortical and cancellous bone, tensile load-deflection (including rupture) properties for the ligaments under various strain rates, and non-linear compressive properties of surrounding muscles, menisci, and cartilage.

\subsection{Injury tolerance and biomesthanical response}

To develop countermeasures for pedestrian protection, either through improvement in vehicle front-end designs or structural enhancements, it is useful to understand the 
injury mechanisms and the tolerance for those injuries. A good understanding of injury mechanism aids in the development of a biomechanical injury criterion to predict the risk of injury when exposed to a crash. Knowledge of injury toleranlece helps to establish Injury Assessment Reference Values (IARV). Further, to extend the understanding of injury tolerances and injury mechanisms to real world assessment of vehicle designs, it is necessary to either develop biofidelic dummies or human mathematical models. To achieve this, biomechanical response corridors hitve to be established for design and validation. The dummy responses should lie within the biomechanical corridors when impacted under similar test conditions.

Krieger et al. [15] also carried out full-seale experimental simulation with cadavers to document the three-dimensional kinematics of vehicle-pedestritun interaction. They measured lincar and angular acceleration of the major boyy segments. Pritz et al. [16] in a series of 15 full-scale experiments at $10-30 \mathrm{mbh}$ reported a critical value of $45 \mathrm{~g}$ 's for the pelvic fracture tolerance. They found 10 correlation between peak bumper forces and injury. In another study comparing the performance of modified Part 572 dummy with that of caldaver, Pritz [17] reported the acceleration-time histories of pelvis, left knee and left foot along with the twodimensional trajectory of kinematics.

In an effort to understand the strain-rate response of ACL and MCL, Aldman et al. [19] conducted tensile tests to determine the ligament stiffness and tensile strengtl]. They reported an ultimate strength of $1.1 \mathrm{kN}$ at an elongation of $3 \mathrm{~mm}$, and a stiffness of $370 \mathrm{~N} / \mathrm{mm}$ for the ACL. The MCL stiffness doubled with increasing strain rate, from $70 \mathrm{~N} / \mathrm{mm}$ (at $6 \mathrm{~mm} / \mathrm{s}$ ) to $150 \mathrm{~N} / \mathrm{mm}$ (at $140 \mathrm{~mm} / \mathrm{s}$ ). Begeman et al. [41] also investigated the viscoelastic response of MCL by subjecting the extended knee to valgus strain. The total streteh varied between $5 \%$ to $15 \%$, and the strain ralle between $157 \% / \mathrm{s}$ to $480 \% / \mathrm{s}$. Averatge failure load was about $2 \mathrm{kN}$. In another study cvaluating the performance of prophylactic knee brace, France and Paulos [4?] evaluated the response of knee ligaments to valgus loading at a low rate $(76 \mathrm{~mm} / \mathrm{sec})$. The contribution of MCL, ACL, and PCL at the onset of MCL rupture was $80 \%$. $11 \%$ and $9 \%$. These results indicated that the MCL experienced tension immediately upon the application of lateral force. With an increase in valgus angulation (medial joint opening) the $\mathrm{ACL}$ and then the PCL began to offer resistance. Also, the tensile test results with MCL indicated that an increase in strain-rate (approx. 12 times) resulted in an increase in the ultimate load $(28 \%)$ and stiffness $(40 \%)$. To initiate MCL injury, a medial joint opening of $7 \mathrm{~mm}$ wats required. To produce rupture $15 \mathrm{~mm}$ was required. Erickson ef al. [43] in a dynamic evaluation of the prophylactic knee brace also confirmed the findings of France and Paulos [42].

In another related study, Yasuda e't al. [44] measured the elongation of the $\mathrm{ACL}$. and MCL simultaneously during lateral impact to whole leg specimens. The findings are summarized as follows: peak elongation of $\mathrm{MCL}$ was $3.25 \%$ at zero knee flexion and $4.25 \%$ al $30^{\circ}$ flexion; peak elongation of the ACL averaged $1.8 \%$ alt zero ${ }^{\circ}$ flexion and $3.8 \%$ at $30^{\circ}$ flexion. The time delay between the peak impact force and peak tension in $\mathrm{MCL}$ averaged $50 \mathrm{~ms}$, and $61 \mathrm{~ms}$ in $\mathrm{ACL}$. The maximum elongation time of $\mathrm{MCL}$ and $\mathrm{ACL}$ depended on the knee flexion angle, $\mathrm{ACL}$. elongation rate increased with the flexion angle. These results may help explain some of the underlying injury mechanisms of the knee joint subjected to a lateral load. 
Fracture tolerance of the tibia has also been investigated. Kramer et al. [14] was among the first to perform a tolerance assessment of the tibia under dynamic loalding in the anterior-posterior direction. Results from 209 cadaver tests showed a wide spread in fracture fores. The authors concluded that a force of $4.3 \mathrm{kN}$ at an impact speed of $7.1 \mathrm{~m} / \mathrm{s}$, and $3.3 \mathrm{kN}$ at $6.3 \mathrm{~m} / \mathrm{s}$ produced a $50 \%$ likelihood of fractures. Bunketorp et al. [20] in an attempt to reproduce the clinical leg injuries with component tests in the lab using whole leg cadaver specimens, reported a fracture tolerance foree of $1 \mathrm{kN}$ or below for the tibia. He noted that high ground friction combined with low contact height increased the fracture risk when the cadaver was simulating a walking stance. Aldman [21] indicated that a bumper force of $4 \mathrm{kN}$ was required to fracture an unloaded tibia, but $1 \mathrm{kN}$ may be enough to fracture a tibia loaded by its body weight. EEVC noted that the lower leg tolerance mainly depended on the tibia, since fibula was a weak bone. They indicated a tolerance value ranging from $3.0 \mathrm{kN}$ to $9.8 \mathrm{kN}$ for the tibia (based on small surface impact), but did not rule out the possibility of higher tolerance to injury when impacted by bumper-like surface. A tolerance value of $200 \mathrm{Nm}$ was suggested for the bending moment. Nycuist ('t al. [45] conducted static and dynamic three point bending tests with twenty-two unembalmed human tibias. The loading was by a $25 \mathrm{~mm}$ rigid cylinder at the tibia midspan in the anterior-posterior and lateral-medial directions. He reported a tolerance value of $320 \mathrm{Nm}$ and $280 \mathrm{Nm}$ for males and females respectively.

Cesari et al. [24,25] conducted twenty cadaver pedestrian tests by varying the impact speed from $20 \mathrm{~km} / \mathrm{h}$ to $39 \mathrm{~km} / \mathrm{h}$, and the bumper height from $60 \%$ (of the lower leg height) to $120 \%$. They reported that leg injuries could occur at a peak bumper foree of $2 \mathrm{kN}$ or less, though the bumper foree was not indicated to be a good predictor of risk. They observed no leg injuries when the knee bend angle was less than 15\%. They indicated that a bumper force of $3.3 \mathrm{kN}$ was associated with long bone fractures, while a foree of $2 \mathrm{kN}$ was not. Most recently Kajzer et al. [28,29] conducted tests with cadaver leg specimens to assess the injury tolerance of the knee to shearing and bending loads. The results of the tests are summarized below in Table 6.

Table 6 Results of shear and bending tests showing the initial damage mechanism [28, 29]

\begin{tabular}{|c|c|c|c|c|}
\hline \multirow[b]{2}{*}{ Test type } & \multicolumn{2}{|c|}{ Impact relocity $=20 \mathrm{~km} / \mathrm{h}$} & \multicolumn{2}{|c|}{ Impart velocity $=40 \mathrm{~km} / \mathrm{h}$} \\
\hline & $\begin{array}{c}\text { Kince shewle forese } \\
(k N)\end{array}$ & $\begin{array}{c}\text { Knese bending mo- } \\
\text { ment (Nm) }\end{array}$ & $\begin{array}{l}\text { Knese sheref force } \\
\qquad(k N)\end{array}$ & $\begin{array}{c}\text { None hending mo- } \\
\text { ment }\left(N^{\prime} m\right)\end{array}$ \\
\hline \multirow[t]{2}{*}{ Shear } & 2.4 & 418 & 2.6 & 489 \\
\hline & \multicolumn{2}{|c|}{ ACL injury initiated } & \multicolumn{2}{|c|}{$\begin{array}{c}\text { Extral-articular fractures of the femur } \\
\text { and tibia (supra-condylar or } \\
\text { diaplisysis fracture) }\end{array}$} \\
\hline \multirow[t]{2}{*}{ Bending } & 1.3 & 307 & 1.5 & 331 \\
\hline & \multicolumn{2}{|c|}{ MCl injury initialled } & \multicolumn{2}{|c|}{$\begin{array}{c}\text { Extrat-aticular fractures } \\
\text { of the fomur }\end{array}$} \\
\hline
\end{tabular}




\section{Discussion}

Batsed on the studies conducted so fiar, several real world injuries to pedestrians hat been reproduced in the lab and the injury mechanisms proposed. But, the ingur? mechanisms of depressed tibial platcatu fractures, supracondylar liactures in hiegh speed impacts, and longitudinal rotation of the pedestrian about the vertical axis ate among the malor issues that rematn unknown.

Based on the knee joint analomy and an understanding of biomechanical loading conditions, one hypothesis of an injury mechanism lor depressed libial plateal fracture caln be proposed here. The lateral and medial condyles are two of the most important articulating surfaces in the knee. The average distance between the centers of contact of the lemoral condyles at the tibia is between thee to four inches. When the lower leg knee is impacted laterally. there may be shear displacement of the this followed by a lateral rotation of the knee joint. This valgus rotation of the knee mat oceur about the lateral condyles, while the hip joint and talus maly become the instantaneous center of rotation for the femur and tibial respectively. This rotation can induce a compressive foree, which may be proportional to the angular acceleration or angulat velocity of the tibia. Fissentially, the impatet forec on the lower leg may induce a vertical acederation of the upper body and thigh (hats bo overeome the vertical resistance offered by the mass of upper body and thigh, Assuming a body mass of $160 \mathrm{lb}$, a vertical acceleration of $1-3$ ges maly result in a vertical force of $160-480 \mathrm{lb}(700 \mathrm{~N}-2100 \mathrm{~N})$. This is well within the range of vertical loads reported in some studies. The injury mechanism is illustrated in Figure is sehematically. Data for angular acceleration and angular velocity of the lower lege alle not commonly reported.

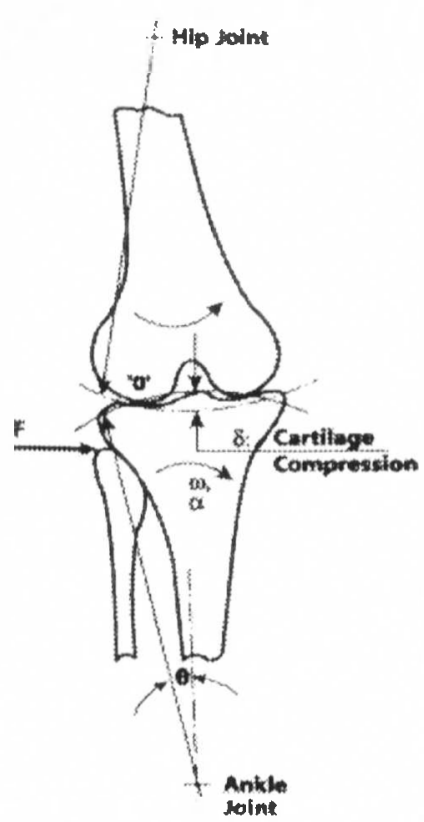

Figure 8 Proposed injury mechanism lon depressed fibial platcia fractures 


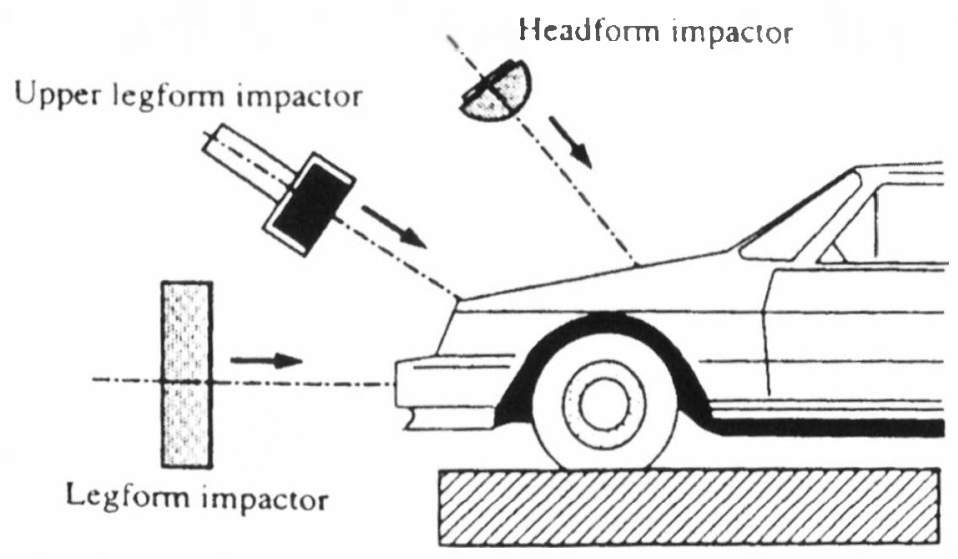

Jigure 9 Sohematic of proposed EEVC regulatory sub-system tests

Next. the injury mechanism for supracondylar fracture of the femur (in Kalyer et al., high-speed shear tests) may be related to the strain-rate effect of ligaments (mainly ACL.). Al high stran-rate, ACL stilfness may be high enough to stress the femoral condyle in shear resulting in fracture. The shear and bending tests conducted by Kajzer" al. reported supratcondylar fratetures all high speed loalding. It is noted that these fractures maly also be related to the test set-up. It is possible that ahe plate measuring the knee reaction foree maly have catused lhese fractures, by edge loading. Instead of a rectangular plate if a cylindrical shaped plate of latge radius wals used. the oulcome maly have been different.

The vertical rotation of the subject in the experimental tests hats been reported. but no platusible explanation hals been rendered so firs. Lower limb FE model simulations reported hy Schuser 40 maty provide some insight to this phemomenom. When cross-cat motion of the pedestrian was simulated at impact. the friction of the leg on the bumper maty have indueed a rotation of the lower limb. It is hypothesized that this intial rotation results in the overall body rotaltion observed in some tests. In at few cases with no cross-car pedestrian motion simulated, less pronounced bower limb rotations were also predicted 10 oceur. These smaller rotations maly be due wo the fact that the leg is not an axi-symmetric body. More muscle on the posterion of the feg maly result in greales foree during the initial phase of an impact. This forece may induce some rotation to the lower leg as the impact proceeds (Figure b).

\section{Conclusions}

Based on the studies reviewed, the following conclusions atre drawn:

1 Though the pedestrian crashes accounted for $1.2 \%$ of all traftic cratshes in United Stales $(1906)$. they atcomonted for $11.3 \%$ of all tratfic latalities. confirming the severity of these crashes. Blood alcohol fevel is an important factor in the fatal crastes with $48 \%$ of the pedestrian litlalities related lo high BAC levels $(>0.1 \mathrm{~g} / \mathrm{d})$. 
2 The pedestrian injuries and fatalities were much higher in other countries such as France, Japan. UK, and Germany. The falalities vary from $11 \%-37 \%$ of all traffic fatalities. Most pedestrian crashes occurred in cities and countries that have high population density and urbanization.

3 Based on the aceident statistics of US and Europe, the elderly (>65 years) and the children ( $<15$ years) were exposed to increased risk of fatalities and involvement in pedestrian crashes. The fatality/injury ates (per 100,000 persons) were high for both the age groups, compared to young to middle-aged adults (15-64 years).

4 Most pedestrian crashes do not take place at intersections. Improper crossing and failure to yield right of way were the main eatuses identified. $\Lambda$ most $50 \%$ of the pedestrian fatalities occurred between $6 \mathrm{pm}-$ midnight, while $64 \%$ of the pedestrian injuries were sustained during the day (6 $\mathrm{AM}-6 \mathrm{PM})$.

5 Passenger cars had the highest involvement rate among vehicles $(70 \%)$ in fatal as well as injurious crashes. In more than $80 \%$ of the pedestrian crashes, the pedestrian was struck on the side (lateral direction) by the oncoming vehicle.

6 Vehicle front bumper, windshield, hood surface, hood edge, and A-pillar were the main velicle-pedestrian contact regions. The bumper was the main contact for lower leg injuries in adults, and femur/pelvis injuries in children. The hood edge was associated with femur/pelvis injuries in adults, and chest/abdomen head injuries in children. The hood surface was associalted with head/chest/am injuries in adults, and head injuries in children. The windshicld surround was the primary source of head injuries in adults.

7 The primary vehicle parameters that influeneed the pedestrian kinematics and responses, were the bumper height, hood-edge height, bumper leald angle, length of hood, angle of hood and windshickl. At a vehicle impact speed of upto $40 \mathrm{~km}$. h: $80 \%$ of all AIS $1-2$ injuries, $60 \%$ of all AIS 3.4 injuries, and $30 \%$ of all AIS 5-6 injuries are represented.

8 The body regions most injured were - the head, the legs, the arms, and the petris When minor injuries (AIS 1-2) were eonsidered, the legs followed by the heald were the most frequently injured body regions, while the legs followed by the head were the most frecuently injured body regions when non-minor injuries (AIS 3-5) were considered. Among the fatal injuries, the head/neck/lace was the most severely injured body part followed by the chest, the abdomen and the pelvis. Injuries to the lower extremity were mostly non-fatal, mal have long-term elfects such as tramatic arthritis.

9) Children were at a higher risk for femur/chest/abdomen/head injuries, while the elderly had higher risk of pelvic fractures compared to adults. For a given erash severity, the elderly were at a higher risk of injury, than children and adults.

Based on the results of experimental studies, injuries to the lower extremities hate becn explained by thee proposed injury mechanisms:

- Contact injuries due to acceleration of the leg (fracture of the femur and/or tibial shatit);

- Injuries associated with the shear forec through the knee joint (ACL rupture avulsion, tibial intercondylar eminence facture, femoral cartilage injury); 
- Injuries associated with the bending moment at the knee joint (compression fracture of lateral femur condyle, tibial platcau fractures, and MCL rupture).

The injury tolerance data and biomechanical corridors can be improved by further biomechanical investigations, and conducting experiments in a controlled environment (for example, to understand load sharing between ligaments). A good understanding of the injury mechanisms and biomechanical tolerance will also enable the development of a biofidelic pedestrian dummy. The development of human math models can also be improved. The literature is sparse, and the hege benefits of math models are yet to be fully realized.

\section{Future work}

- Use the new finite element (FE) models of the lower extremity to understand and predict injury mechanisms under different loading conditions - for example, cartilage damage, extent of ligament rupture, and capsule stretch.

- The accident data from epidemiological studies are old. Further studies have to be conducted to assess the influence of changing vehicle designs, changing demographics, and changing composition of the fleet on the nature and frecuency of injuries.

- It may be beneficial to determine the viscoelastic characteristics and load sharing between different ligaments of the knee, in high-speed lateral loading under different impact conditions. This will aid in further understanding of injury mechanisms, development and validation of mathematical/CAE models, and finally lead to improved biomechanical injury criteria.

\section{References}

1 NIITSA Trallic Salfely Facts $(1996,2001)$ 2000, DOT HS 809 329. US Department of Transportation.

2 IRTAD (1999) 1997 International Road Traffic \& Accident Database.

3 Isenberg, R.A., Walz, M., Chidester, C. and Kanfman, R. (1996) Pedestrian crash data

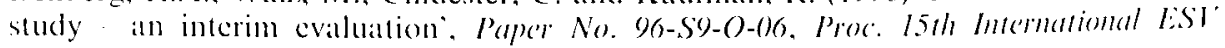
Conference. pp. 1396, 1407.

4 Isenberg, R.A., Chidester, C. and Mavros, S. (1998) 'Update on the pedestrian crash data study". I'aper No. 9S-S6-O-0.5. Proce. Loth Intermetional EST' Conference.

5 Jarrett, K.L. and Saul, R.A. (1998) Pedestrian injury an analysis of the PCDS lield collision data', Paper No. 99-S6-0-0)4. Proc. Loth International EST Conference'.

6 Hatruff, R.C., Avery, A. and Alter-Pandya, A.S. (1998) Analysis of circumstances and

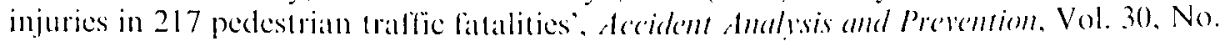
1. pp. 11.20.

7 EEVC Working (iroup (1982) 'Pedestrian injury accidents', Proc. 9th Intemational ESI' Conference, pp. 6.38671 .

8 Ohashi, H., Ono, K.. Sasaki. A., Ohashi, N. and Misawa, S. (1990) "The present

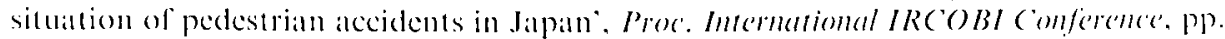
283291 . 
9 Ashton, S.J. (1986) "Child occupant and child pedestrian leg injuries', SAE Paper No.

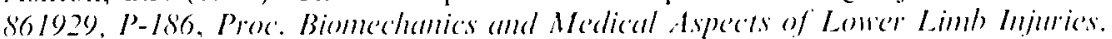

10 Matsui, Y., Ishikawa, H. and Sasaki, A. (1999) Pedestrian injuries indaced by the bonnet leading edge in current car-pedestrian accidents. SAE P(4Po' $N($. $/ 990-() /-(1) 7 / 3$. $S P-1432$.

11 Otte, D. (1994) "Influence of the fronthood length for the silfety of pedestrians in car accidents and demands to the safety of small vehicles". SalE Paper No. 9.42.32.

12 Sakurai, M., Kobalyashi, K. and Ono, K. (1994) 'Evaluation of pedestrian protection test procedure in Japan - influence of upper body mass on leg impact test'. P'aper No. 9f-S7O-()I, Proc. 14th International EST Conference, pp. 11141130.

13 Chapman. A.J., Wade, F.M. and Foot, H.C. (Eds) (1982)'Vehicle design and pedestrian injuries". in: Pedestrian Accidents, S.J. Ashton (Ed.), John Wilcy \& Sons, pp. 169) 202.

14 Kramer, M. Burow, K. and Hegar, A. (1973) 'Fracture mechanism of lower legs under impact load', SAE Paper 730960, 17/h Stapp Car Crash Conferences pp. 81 100.

15 Krieger, K.W., Padgatonkar, A.J. and King, A.I. (1976) Full-scalle experimental simulation of pedestrian vehicle impacts", SAE Paper No.76018/3.

16 Pritz, H.B., Hassler, C.R., Herridge, J.T. and Weis, E.B. Jr. (1975) 'Experimental study of pedestrian injury minimization through velicle design", SAE Paper 75/l6o, Pros. IOth Stapl) Car Crash Conference, pp. 725-751.

17 Pritz. I. В. (1978) Comparison of the dynamic responses of anthropomorphic test devices

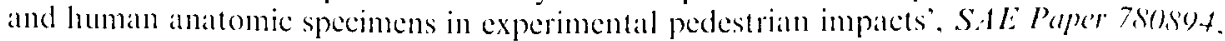
Proc. 22nd Stapl Car Crash Conforence. pp. 343356.

18 Eppinger, R.II. and Prity, H.B. (1979) - Development of a simplified velicke performance requirement for pedestrian injury mitigation'. Proc. 7th Hermatonal Tedmical conference on Experime'ntal Safery. L'ehickes. pp. 713-723.

19 Aldman, B., Thomgren, L., Bunketorp, O. and Romanus, B. (1980) An experimental model system for the study of lower leg and knee injuries in car pedestrian atcedents.

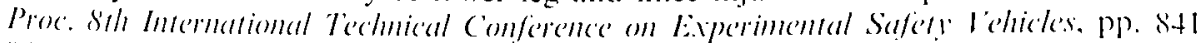
849.

20) Bunketorp, ()., Aldman, B., Thorngren, L. and Romansu, B. (1982) '(linical and experimental studies of leg injuries in car-pedestrian accidents", P'roc. Oth Imtrinational

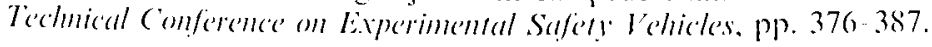

21 Aldman, B. (1984) Limbs: kinematics, meclanies of injury, tolerance levels, and protection criterial for car oceupants, pedestrians, and two-wheclers", in: Biomechemica of Impart Trama, B. Aldman and $\Lambda$. Chapon (Eds), Amsterdam: Blsevier Science Publishers B.V., pp. 327-331.

22 Manoli, A. (1986) 'Adult podestrian injuries medical aspects", SAE Paper sol92S. P-1S6. Biomechanics and Medical Aspeects of Loner Limb Injurie's, pp. $109-114$.

23 Kallieris, D), and Schmid, (j. (1988) 'New aspects of pedestrian protection: loadding and injury pattern in simulated pedestrian accidents', SAl: Paper S81725, Proc. 32nd Siap" Car Cirash Conference, pp. 185196.

24 Cesalri, D., Cavallero, C., Cassan, F, and Moffatt, C. (198s) 'Interatetion between human

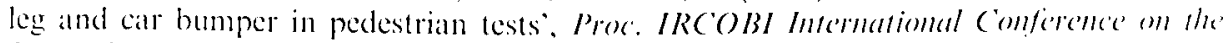

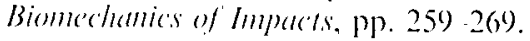

25 Cesarti, D., Cavallero, C. and Roche, H. (1989) 'Mechanisms producing lower extremity injuries in pedestrian accident situations', 3.3rd Ammul Pros. Association for the

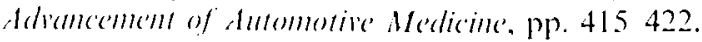

26 Kajzer, J., Cavaltero, C.. Ghanomchi, S., Bomnoit, J. and Ghorbel, A. (19)(0) 'Response of the knee joint in lateral impact ellect of slearing loads", Proce IRC'OBI Internatiomal Conference on the Biomedhanics of Impersts, pp. 293304.

27 Kajzer, J., Cavallero, C.. Bonnoil, J., Morjane, A. and Ghanouchi, S. (199)3) 'Response of' 
the knee joint in lateral impact effect of bending moment', Proc. IRCOBI Imtrmational Conference on the Biomedhanics of lmpacts, pp. 105116.

28 Kajger, J., Schroeder. G., Ishikawa, H., Matsui, Y. and Bosch, U. (1997) 'Shearing and bending effects at the knee joint at high speed lateral loadting". SAE Paper 9733326. Pros. 4lst Siapp Cot Crash Conference, pp. 151-165.

29 Kajzer, J.. Matsui, Y., Jshikawa, H., Schroeder, G. and Bosch, U. (1999) 'Shearing and bending effects at the knee joint at low speed lateral loading, SAE Paper No. I999-0/(1) $7 / 2$.

30 Paldgalonkar. A.J., Krieger, K.W. and King, A.I. (1977)'A three-dimensional mathematical simulation of pedestrian vehicle impact with experimental verification", Journal of Biomerhanical Enginesring, pp. 116-123.

31 Wismans, J., Van Wijk. J. (1982) "Mathematical models for the assessment of pedestrian protection provided by a car contour', Proce. 9th International Tedmical conferencer on Exporinnental Safert. V'olickes, pp. 205213.

32 Van Wijk. J., Wismans, J., Maltha, J. and Wittebrood, L. (198.3) 'MADYMO pedestrian simulations', SAE Paper in P-12I, Pedestrian Impact Injury \& Assessmem, pp. 109 117.

33 Yang, J.K., Rzymkowski, C. and Kajzer, J. (1993) 'Development and validation of a mathematical breakable leg model', Proc. 1993 IRCOBI International Conference on the' Biomechanics of Impacts, pp. 175186.

34 Yang, J.K. and Kaljer, J. (1992) 'Computer simulation of impact response of the human response of the human knee joint in carr-pedestrian aceidents", SAE Paper 922525, Proc. $36 t h$ Stapl cear Crash Conforence, pp. 203-217.

35 Yang, J.K., Kajzer, J., Cavallero, C. and Bomnoit. J. (1995) 'Compuler simulation of shearing and bending response of the knee joint to a lateral impact, SAL Paper 952727.

36 Bermond, F., Ramet, M., Boucuet, R. and Cesari, D. (1993) A finite element model of the pedestrian knee-joint in lateral impact", Proc. 1993 IRCOBI International Conferenes on the Biomednamies of Impacts, pp. 117 129.

37 Bermond, IF., Ramet, M., Boupuet, R. and Cesari, D. (1994) 'A finite element model of the pedestrian leg in lateral impact, Proce. Ithe International Tedmical conference on Enhanced Safoly of l'dircles, pp. 199209.

38 Yang, J.K., Witlek, $\Lambda$. and Kaj/er, J. (1996) 'Finite element model of the human lower extremity skeleton system in lateral impact", Proc. IRCOBI International Confierence on the Biomechanics of limparts, pp. 377.388.

39 Schuster, P.J., Chou, C.C., Prasald, P. and Jayaraman, G. (2000) 'Development and validation of a pedestrian lower limb non-linear 3-D finite element model'. SAl: Paper

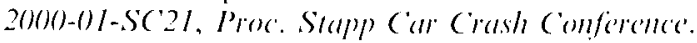

40 Takahashi, Y., Kikuchi, Y.. Konosu. A. and Ishikawal, II. (20)(0) 'Development and valielation of the finite element model for the human lower limb of pedestrians". SAE

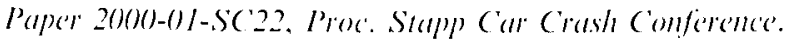

41 Begeman, P.C., Kopace, J., Hardy, W., Levine, R.S. and King, A.I. (1986) 'Strains and forces in the human medial collateral ligament during lateral impact, ASMI: Transuctions, pp. 233236.

42 Jiance, E.P. and Patulos, L.L. (I) $(0)$ ) In vitro assessment of prophylatetic knec brace function", Clinics in Sports Medicinc, Vol. 9. No, 4. pp. 823829.

43 Erickson, A.R., Yastada, K., Beynnon, B., Johnson, R. and Piope, M. (19)3) 'An in vitro dynamic evaluation of propliylactic knee braces during lateral impact loading", dmetican Jommal of Sprorts dedicine, Vol. 21, No. 1, pp. 2635.

44 Yasuda, K., Erickson, A.R., Beynnon, B.D., Johnson, R.J. and Pope, M.II. (1993) 'Dynamic elongation behavior in the medial collateral and anterior eraciate ligaments

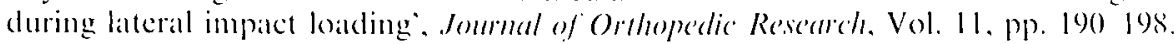

45 Nycluist. G.W., Cheng, R., El-Bolny, A.A.R. and King, A.I. (1985) Tibia bending 
strength and response', SAE Paper 851728, Proc. 29th Stapp Car Crash Conference, pp. $99-112$.

46 Schuster. P.J. (2000) Evaluation of the real-world injury-reduction potentiat of the proposed European pedestrian "leg-lorm" impact test using a detailed linite element model of the lower limb", Doctoral Dissertation, Michigan Technological University. 